\title{
Effect of Cell Size on the Fundamental Natural Frequency of FRP Honeycomb Sandwich Panels
}

\author{
Sourabha S. Havaldar ${ }^{1}$, Ramesh S. Sharma ${ }^{1 *}$, Arul Prakash M. D. Antony ${ }^{2}$, Mohan Bangaru ${ }^{2}$ \\ ${ }^{1}$ Department of Mechanical Engineering, R. V. College of Engineering, Bangalore, India \\ ${ }^{2}$ Department of Production Technology, Madras Institute of Technology, Chennai, India \\ Email: *rssharma25@yahoo.com
}

Received January 7, 2012; revised February 10, 2012; accepted March 5, 2012

\begin{abstract}
In the present work, the effect of hexagonal cell size of the core on the fundamental natural frequency of FRP honeycomb sandwich panels has been analyzed both experimentally and by finite element technique. Experimental Modal tests were conducted on hexagonal cell honeycombs ranging in size from $8 \mathrm{~mm}$ to $20 \mathrm{~mm}$ maintaining the facing thickness constant at around $1 \mathrm{~mm}$ with two different boundary conditions viz C-F-F-F and C-F-C-F. The traditional "strike method" has been used to measure the vibration properties. The modal characteristics of the specimens have been obtained by studying its impulse response. Each specimen has been subjected to impulses through a hard tipped hammer which is provided with a force transducer and the response has been measured through the accelerometer. The impulse and the response are processed through a computer aided FFT Analyzing test system in order to extract the modal parameters with the aid of software. Theoretical investigations have been attempted with appropriate assumptions to understand the behavior of the honeycomb sandwich panels during dynamic loading and to validate experimental results. Finite Element modeling has been done treating the facing as an orthotropic laminate and Core as orthotropic with different elastic constants as recommended in the literature. The results are presented which show that the theoretical model can accurately predict the fundamental frequency and how honeycombs with different cell size will perform under dynamic loads.
\end{abstract}

Keywords: Honeycomb; Modal Testing; FRP; Impulse; Frequency

\section{Introduction}

Sandwich structures that employ a honeycomb core between two relatively thin skins are desirable in several engineering applications that require high strength to weight ratios. Because of their ability to absorb large amounts of energy, they are also often used as a "cushion" against external loads. Honeycomb sandwich structures are currently being used in many engineering applications, both within and outside of aerospace engineering. Lightweight honeycomb materials can be used in the construction of composite panels, shells, and tubes with high structural efficiency.

In recent years, the researches pertaining to honeycomb sandwich structures have been focused on effective numerical modeling methods, vibration properties, crashworthiness, damage, failure and impact response [1,2]. Burton and Noor $[3,4]$ investigated the continuum modeling of honeycomb sandwich for computation. Nieh [5] also studied the processing and modeling of cellular solids for lightweight structures. Maheri and Adams [6]

${ }^{*}$ Corresponding author. investigated the damping of composite honeycomb sandwich beams in steady-state flexural vibration using the method extended from that for monolithic beams. Goldsmith et al. $[7,8]$ studied the crashworthiness of honeycomb under impact loads. Neilsen [9] discussed the continuum representations of cellular solids, including honeycomb materials, to relate localized deformations to appropriate constitutive descriptions. But the role of anisotropic properties of honeycomb core in elasticity on the structure was not addressed.

Damping contributions due to its components, particular skin fiber orientations, were considered. They also investigated the dynamic shearing property of both Nomex and aluminum honeycomb core [10]. The dynamic shearing properties of honeycomb were shown to be different in various directions from static properties. It has long been realized that honeycomb materials are anisotropic in nature. The ability to predict the properties of these cellular materials depends on the knowledge of microstructural mechanism that contributes to macroscopic behavior. The traditional Nomex and aluminum cores have great capability of withstanding compression 
load in thickness $(T)$ direction and shear load in longitudinal $(L)$ and width $(W)$ directions. The material properties such as elastic moduli and strengths are various in different directions, and even the compressive and tensile properties are different in the thickness-direction, primarily due to the initial deflection of cell walls. Vibration frequencies and mode shapes of honeycomb sandwich panels with various structural parameters were studied by Qunli Liu and Yi Zhao [11] using computational and experimental methods. Two computational models were used to predict the mode shapes and frequencies of honeycomb sandwich panels. Plate elements were used for honeycomb cell walls to reflect the geometric nature of the hexagonal cells. The quantitative effect of the anisotropic core on the vibration properties of the sandwich panels were studied and presented.

Most studies in the literature are related to one of the attributes (high strength/weight or increased energy absorption) mentioned above. With regard to the development of a honeycomb panels, one issue that has been overlooked is the scaling of honeycomb properties with respect to cell size. The variation in cell size may have a large influence on the dynamic properties of honeycomb panels. The current paper expands upon this study. The results from the experimental program will be presented and discussed. The theoretical literature available [12] on sandwich panels in evaluating fundamental frequency with a non-dimensional parameter will also be discussed in this work. Of interest in this study is to understand the effect of cell size on the fundamental frequency of honeycomb panels.

\section{Experimental Techniques}

\subsection{Fabrication of Honeycomb Panels}

FRP honeycomb sandwich panels have been fabricated through vacuum bag molding technique, which uses the vacuum to eliminate the entrapped air and excess resin. The adhesive used is epoxy resin LY 556 mixed with hardener HY 951. The resin and hardener is mixed in the weight ratio of 10:1. To maintain optimum strength of the matrix, the ideal resin to glass ratio is found to be 35:65. The mold used is a "hexagonally machined split molding tool" made of chromium plated mild steel. After ensuring the surface is clean and free from foreign particles, a coat of release agent is applied. A coat of resin mixture is then applied on the molding surface and the plain weave glass "E" fabric is impregnated against the first half of molding tool surface, by ensuring thorough wetting of glass cloth. Subsequently the hexagonal mandrel is placed in the respective slots by pushing the glass cloth down into the half hexagonal slot of the molding tool (Figure 1). Pressure is applied to the wet laid-up laminate in order to improve its consolidation. This is achieved by sealing the wet laid up laminate with a perforated plastic film and placing an absorbent over the perforated plastic film. Above this, a film is placed and sealed which constitutes vacuum bagging process. At one corner of the bag, a port for vacuum is arranged and subjected to a pressure of $450-500 \mathrm{~mm} \mathrm{Hg}$ is applied for 120 minutes to consolidate and to increase the inter laminar shear strength of layers.

\subsection{Specimen Details}

Four different cell sizes viz 8, 16, 20 and $25 \mathrm{~mm}$ honeycomb sandwich panels were prepared to study their influence on the dynamic characteristics. Figure 2 below depicts the honeycomb panel preparation.

After the cure process, test specimens are cut from the size $1000 \mathrm{~mm} \times 1000 \mathrm{~mm} \times 8 \mathrm{~mm}$ by using a diamondimpregnated wheel, cooled by running water. The types of specimens investigated in this study are in the form of plates. The specimens are cut with effective dimensions $100 \times 100 \mathrm{~mm}$ to obtain cantilever condition (Figure 3). Similarly, another specimen was prepared for C-F-C-F condition and is as shown in Figure 3.

\subsection{Modal Test Method}

The modal characteristics of the specimen have been obtained by studying its impulse response. The specimen was fixed at one end to simulate the clamped-free-freefree $(\mathrm{C}-\mathrm{F}-\mathrm{F}-\mathrm{F})$ condition as shown in Figure 3 . The
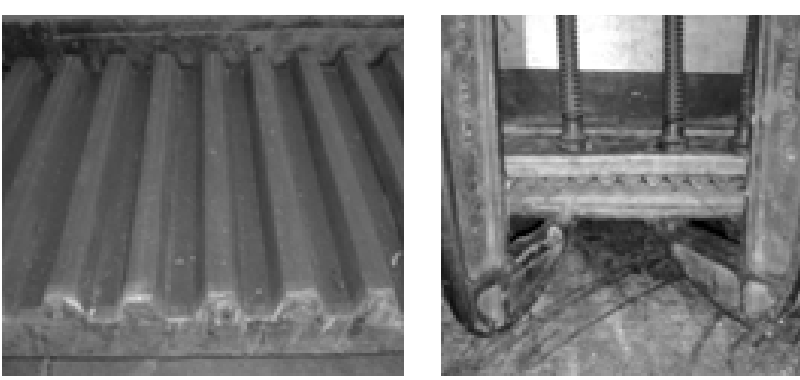

Figure 1. Mould for making the honeycomb core.

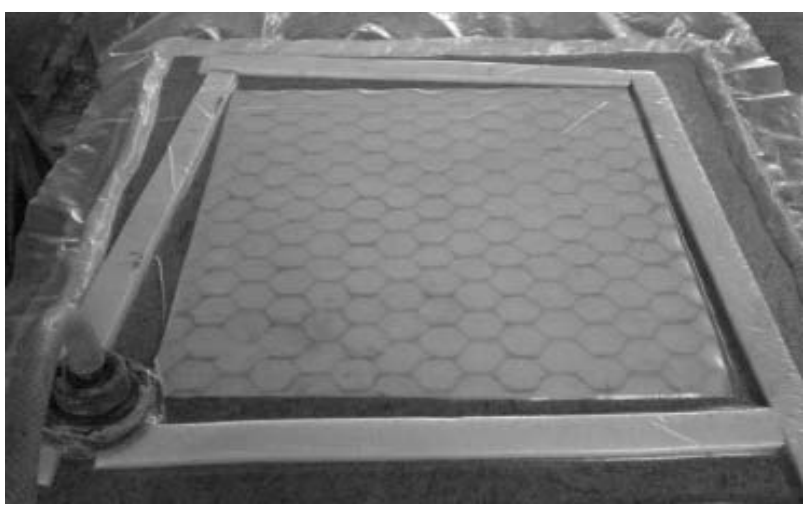

Figure 2. Preparation of honeycomb panel. 


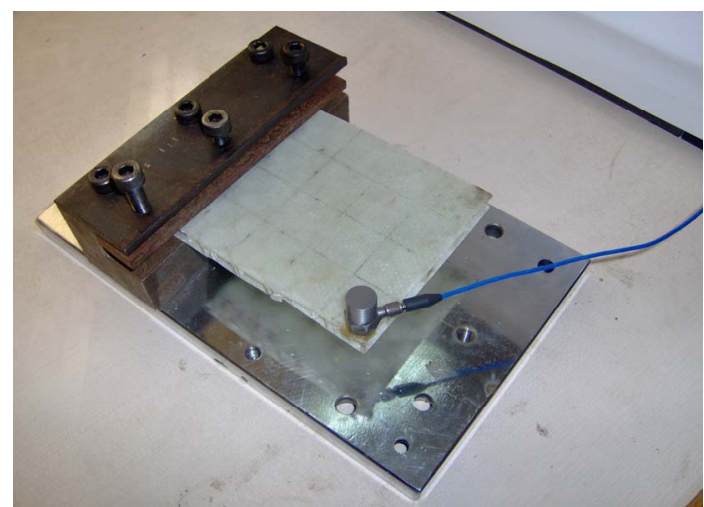

C-F-F-F condition

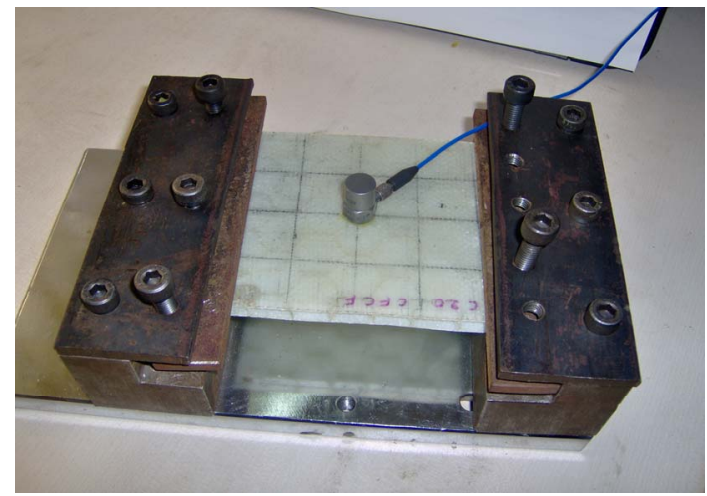

C-F-C-F condition

Figure 3. Specimens attached to fixture for simulating C-FF-F \& C-F-C-F condition. specimen has been subjected to impulses through a hard tipped hammer which is provided with a force transducer (PCB make) with a sensitivity of $2.25 \mathrm{mV} / \mathrm{N}$ and the response has been measured through the accelerometer (PCB make) with an accelerometer of sensitivity 10 $\mathrm{mV} / \mathrm{g}$. The impulse and the response are processed on a computer aided FFT analyzer test system (LMS Inc.) in order to extract the modal parameters with the help of built in software.

The sandwich specimen has been subjected to impulses at 25 station locations. The response has been measured by placing the accelerometer at station 1 . Due to inherent damping in the specimen, the test was restricted to fundamental vibration mode with the impact hammer. The test was conducted for all the types of specimen with two different boundary conditions and the results recorded.

\section{Results \& Discussions}

The physical and chemical tests such as density test, Glass transition test and chemical tests conducted on FRP face sheet is indicated in Table 1. The geometric details of the specimens used for C-F-F-F and C-F-C-F boundary conditions in the modal tests are indicated in Tables 2 and 3.

The elastic properties of the fiber and resin are indicated in Table 4. The elastic constants of the FRP biwoven laminate are obtained from the equations listed in

Table 1. Physical and chemical test of FRP face sheet.

\begin{tabular}{|c|c|c|c|c|}
\hline Specimen designation & Specimen dimensions in $\mathrm{mm}$ & Volume in $\mathrm{m}^{3}$ & Mass in $\mathrm{Kg}$ & Density in $\mathrm{Kg} / \mathrm{m}^{3}$ \\
\hline \multicolumn{5}{|c|}{ Density as per ASTM C 271} \\
\hline \multirow[t]{3}{*}{ FRP } & $25.2 \times 25.3 \times 2.1$ & $1.3389 \times 10^{-6}$ & $2.156 \times 10^{-3}$ & 1610 \\
\hline & \multicolumn{3}{|c|}{ Glass content in FRP: $70 \%$; Resin content: $30 \%$} & \\
\hline & \multicolumn{3}{|c|}{ Glass Transition $\left(T_{g}\right)$ Temperature of FRP as per ASTM D 3418 - 99: $111.29^{\circ} \mathrm{C}$} & \\
\hline
\end{tabular}

Table 2. Geometric details of the sandwich panel (C-F-F-F).

\begin{tabular}{cccccc}
\hline Designation & Length $\times$ width $\mathrm{mm}$ & Facing thickness $\mathrm{mm}$ & Core cell size mm & Wall thickness mm & Core thickness mm \\
\hline C-8 & $100 \times 100$ & 0.92 & 8 & 0.1 & 7.96 \\
C-16 & $100 \times 100$ & 1.00 & 16 & 0.1 & 8.35 \\
C-20 & $100 \times 100$ & 0.96 & 20 & 0.1 & 6.48 \\
\hline
\end{tabular}

Table 3. Geometric details of the sandwich panel (C-F-C-F).

\begin{tabular}{ccccc}
\hline Designation & Length $\times$ width mm & Facing thickness mm & Core cell size mm & Wall thickness mm \\
\hline C-8 & $100 \times 100$ & 0.95 & 8 & 0.1 \\
C-16 & $100 \times 100$ & 0.94 & 16 & 0.1 \\
C-20 & $100 \times 100$ & 0.98 & 20 & 0.1 \\
\hline
\end{tabular}


the appendix and are tabulated in Table 5.

The elastic constants of the FRP honeycomb core have been determined as per the equations listed in the appen dix and are tabulated in Table 6.

For the FE modeling, 20 noded SOLID 95 element was used. The elastic constants and mass density for Facing layer and core layer were appropriately given. Finite Element analysis results are indicated in Figures 4-9 and the consolidated results of the predicted and experimental results are indicated in Table 7. It can be

Table 4. Elastic properties of fiber and resin of Unidirectional FRP facings.

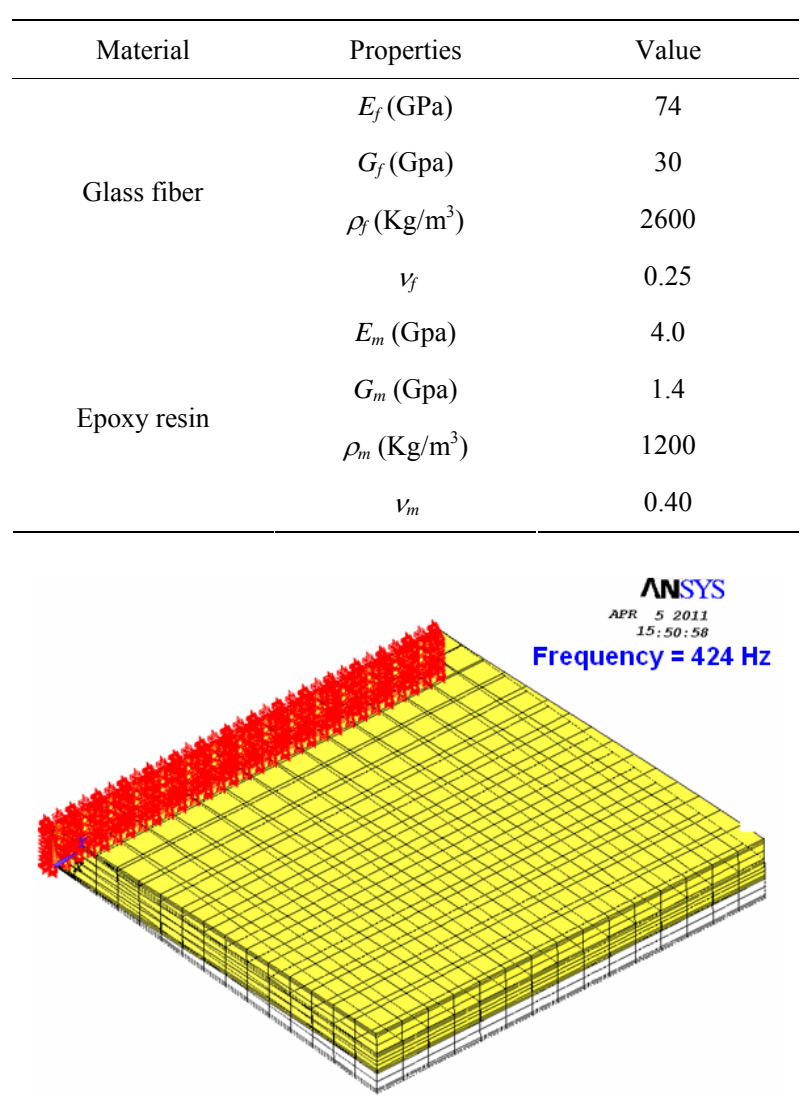

Figure 4. FE model cell size 8-C-F-F-F.

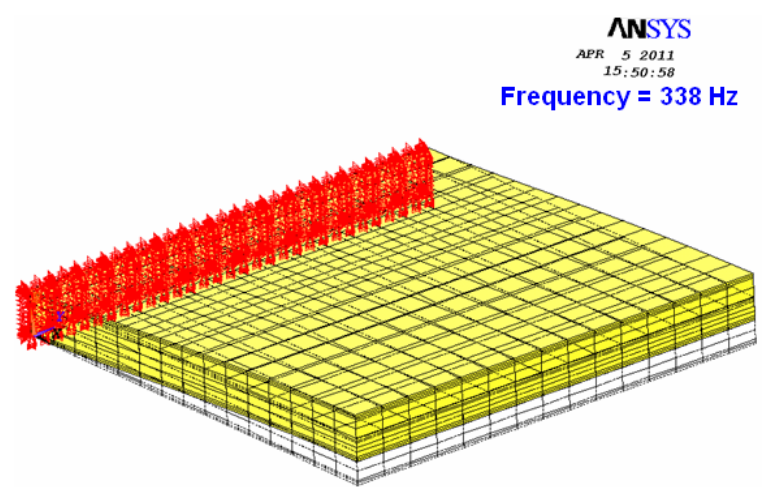

Figure 5. FE model cell size 16-C-F-F-F.

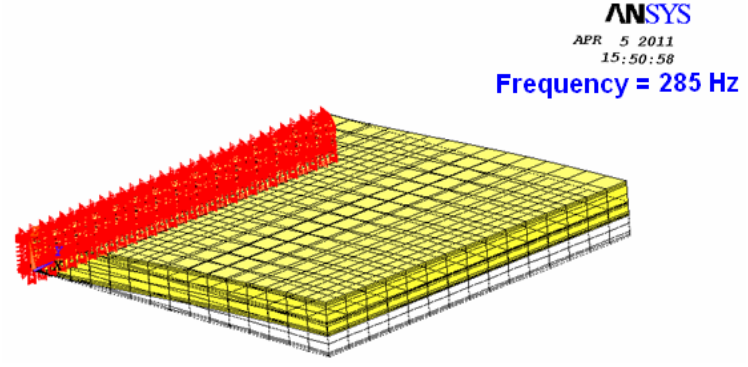

Figure 6. FE model cell size 20-C-F-F-F.

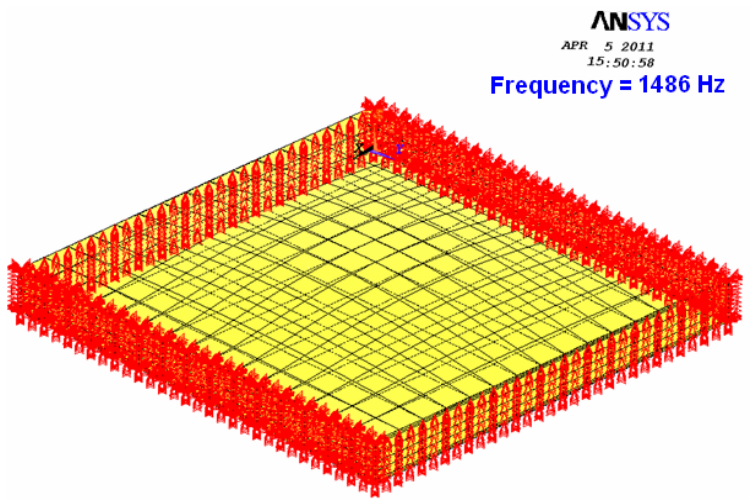

Figure 7. FE model cell size 8-C-F-C-F.

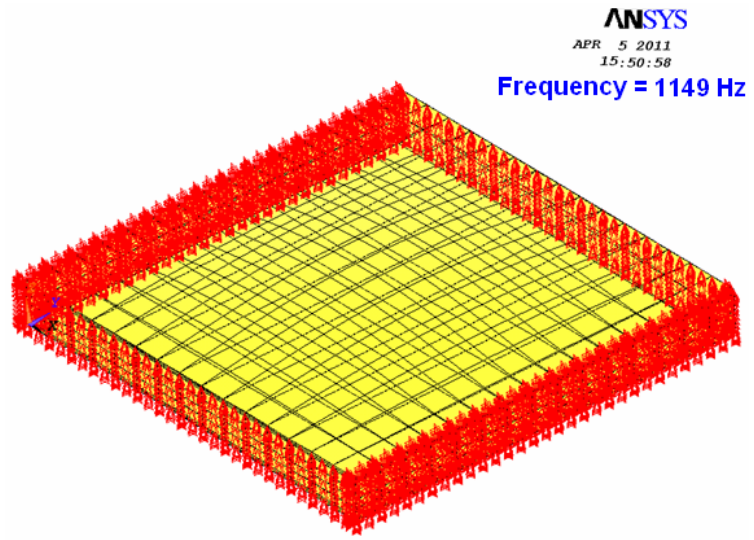

Figure 8. FE model cell size 16-C-F-C-F.

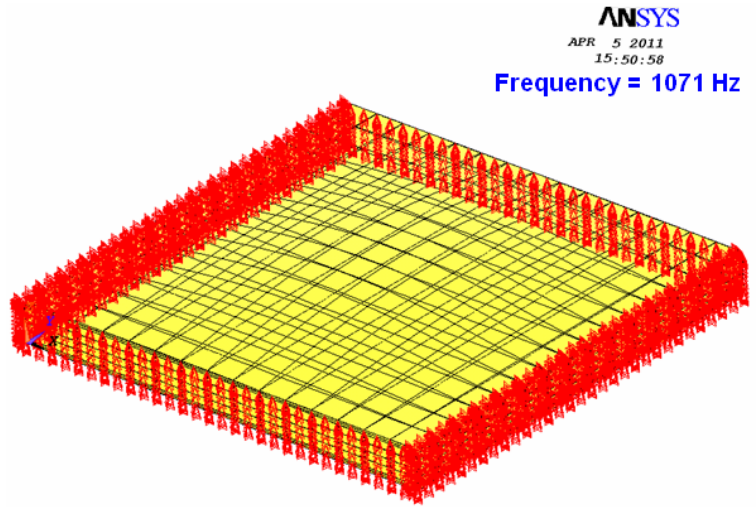

Figure 9. FE model Cell size 20-C-F-C-F. 
Table 5. Elastic properties of the bi-woven FRP facings.

\begin{tabular}{cccccccc}
\hline $\begin{array}{c}E_{1}\left(\mathrm{~N} / \mathrm{m}^{2}\right) \\
\times 10^{9}\end{array}$ & $\begin{array}{c}E_{2}\left(\mathrm{~N} / \mathrm{m}^{2}\right) \\
\times 10^{9}\end{array}$ & $\begin{array}{c}E_{3}\left(\mathrm{~N} / \mathrm{m}^{2}\right) \\
\times 10^{9}\end{array}$ & $\begin{array}{c}G_{12}\left(\mathrm{~N} / \mathrm{m}^{2}\right) \\
\times 10^{9}\end{array}$ & $\begin{array}{c}G_{23}\left(\mathrm{~N} / \mathrm{m}^{2}\right) \\
\times 10^{9}\end{array}$ & $\begin{array}{c}G_{13}\left(\mathrm{~N} / \mathrm{m}^{2}\right) \\
\times 10^{9}\end{array}$ & $\begin{array}{c}v_{13} \\
v_{23}\end{array}$ \\
\hline 16.84 & 16.84 & 7.78 & 2.46 & 2.38 & 2.38 & 0.15 \\
\hline
\end{tabular}

Table 6. Elastic properties of FRP honeycomb core.

\begin{tabular}{cccccccccc}
\hline $\begin{array}{c}\text { Cell size and } \\
\text { density }\left(\mathrm{Kg} / \mathrm{m}^{3}\right)\end{array}$ & $\begin{array}{c}E_{x}\left(\mathrm{~N} / \mathrm{m}^{2}\right) \\
\times 10^{5}\end{array}$ & $\begin{array}{c}E_{y}\left(\mathrm{~N} / \mathrm{m}^{2}\right) \\
\times 10^{5}\end{array}$ & $\begin{array}{c}E_{z}\left(\mathrm{~N} / \mathrm{m}^{2}\right) \\
\times 10^{8}\end{array}$ & $\begin{array}{c}G_{x y}\left(\mathrm{~N} / \mathrm{m}^{2}\right) \\
\times 10^{4}\end{array}$ & $\begin{array}{c}G_{y z}\left(\mathrm{~N} / \mathrm{m}^{2}\right) \\
\times 10^{6}\end{array}$ & $\begin{array}{c}G_{x z}\left(\mathrm{~N} / \mathrm{m}^{2}\right) \\
\times 10^{6}\end{array}$ & $v_{x y}$ & $v_{y z}$ & $v_{x z}$ \\
\hline C-8 $(53.7)$ & 3.940 & 3.940 & 3.64 & 5.92 & 18.4 & 12.7 & 0.994 & 0.0001 & 0.0001 \\
C-16 (26.8) & 0.490 & 0.490 & 1.82 & 68.3 & 9.22 & 6.15 & 0.994 & 0.0001 & 0.0001 \\
C-20 (21.47) & 0.252 & 0.252 & 1.46 & 0.379 & 7.38 & 4.92 & 0.994 & 0.0001 & 0.0001 \\
\hline
\end{tabular}

Table 7. Comparison of experimental and predicted first natural frequency.

\begin{tabular}{ccccccc}
\hline \multirow{2}{*}{ Cell size } & \multicolumn{3}{c}{ CFFF } & & \multicolumn{2}{c}{ CFCF } \\
\cline { 2 - 7 } & $f_{\text {Ansys }}$ & $f_{\text {Actual }}$ & Error & $f_{\text {Ansys }}$ & $f_{\text {Actual }}$ & Error \\
\hline C-8 & 424 & 404 & $4.95 \%$ & 1486 & 1492 & $0.04 \%$ \\
C-16 & 338 & 326 & $3.7 \%$ & 1149 & 1291 & $11.9 \%$ \\
C-20 & 284 & 278 & $2.2 \%$ & 1071 & 1194 & $11.7 \%$ \\
\hline
\end{tabular}

Error $=\left|\frac{f_{\text {Actual }}-f_{\text {Ansss }}}{f_{\text {Actual }}}\right| \times 100$.

seen that the predicted results are in close agreement with the experimental results, the error being less than $12 \%$. It can be inferred that the elastic constants of the core and facings have to be rigorously worked out to predict the fundamental frequency.

\section{Conclusion}

The fundamental frequencies of FRP honeycomb core with different cell sizes under two different boundary conditions viz. C-F-F-F and C-F-C-F have been determined by experimental modal analysis using impulsestrike technique. Finite Element analysis with appropriate elastic constants rigorously worked out for the facings and the core predicts the fundamental frequencies which are quite close to the experimentally determined values.

\section{Acknowledgements}

The authors thankfully acknowledge the Management, Principal of their respective institutions for their constant encouragement and support to carry out this work.

\section{REFERENCES}

[1] P. H. W. Tsang and P. A. Lagace, "Failure Mechanisms of Impact-Damaged Sandwich Panels under Uniaxial Compression," 35th AIAA/ASME/ASCE/AHS/ASC Structures, Structural Dynamics and Materials Conference, Hilton
Head, 18-20 April 1994, pp. 745-754.

[2] P. A. Lagace and J. E. Williamson, "Contribution of the Core and Facesheet to the Impact Damage Resistance of Composite Sandwich Panels," 10th DOD/NASA/FAA Conference on Fibrous Composites in Structural Design, Hilton Head, April 1994, pp. II53-II74.

[3] W. S. Burton and A. K. Noor, "Assessment of Computational Models for Sandwich Panels and Shells," Computer Methods in Applied Mechanics and Engineering, Vol. 124, No. 1-2, 1995, pp. 125-151. doi:10.1016/0045-7825(94)00750-H

[4] W. S. Burton and A. K. Noor, "Assessment of Continuum Models for Sandwich Panel and Honeycomb Cores," Computer Methods in Applied Mechanics and Engineering, Vol. 145, No. 3-4, 1997, pp. 341-360. doi:10.1016/S0045-7825(96)01196-6

[5] T. G. Nieh, "Processing and Modeling of Cellular Solids for Light-Weight Structures," Lawrence Livermore National Laboratory Report UCRL-ID-129666, Livermore, 1997.

[6] M. R. Maheri and R. D. Adams, "Steady-State Flexural Vibration Damping of Honeycomb Sandwich Beams," Composites Science \& Technology (UK), Vol. 53, No. 3, 1994, pp. 333-347.

[7] W. Goldsmith and J. L. Sackman, "An Experimental Study of Energy Absorption in Impact on Sandwich Plates," International Journal of Impact Engineering, Vol. 12, No. 2, 1992, pp. 241-262. doi:10.1016/0734-743X(92)90447-2

[8] W. Goldsmith and J. L. Sackman, "Dynamic Energy Ab- 
sorption of Sandwich Structures by Inelastic Deformation," Technical Report: AFOSRTR-91-033, Washington DC, 1991.

[9] M. K. Neilsen, "Continuum Representations of Cellular Solids," DOET Technical Report No. Sand-93-1287, Washington DC, 1993.

[10] R. D. Adams and M. R. Maheri, "Dynamic Shear Properties of Structural Honeycomb Materials," Composites Science and Technology, Vol. 47, No. 1, 1993, pp. 15-23. doi:10.1016/0266-3538(93)90091-T
[11] Q. L. Liu and Y. Zhao, "Role of Anisotropic Core in Vibration Properties of Honeycomb Sandwich Panels," Journal of Thermoplastic Composite Materials, Vol. 15, No. 1, 2002, pp. 944-952.

[12] R. D Blevins, "Formulas for Natural Frequencies and Mode Shape," Krieger Publishing Company, Melbourne, 1979.

[13] L.-J. Xia, X.-F. Jin and Y.-B. Wang, "The Equivalent Analysis of Honeycomb Sandwich Plates for Satellite Structure," 2001. http://www.mscsoftware.com 


\section{Appendix}

Density of unidirectional lamina

$$
\begin{gathered}
\rho_{c}=\rho_{f} * v_{f} *+\rho_{m} * v_{m}=\rho_{f} * v_{f} *+\rho_{m}\left(1-v_{f}-v_{m}\right) \\
\rho_{\text {core }}=\rho_{\text {frp }} \frac{8 t}{c}
\end{gathered}
$$

Elastic constants of Uni-directional lamina

$$
\begin{gathered}
E_{1}=E_{f} * v_{f}+E_{m} * v_{m} \\
E_{2}=E_{m} *\left[\frac{E_{f}+E_{m}+\left(E_{f}-E_{m}\right) * v_{f}}{E_{f}+E_{m}-\left(E_{f}-E_{m}\right) * v_{f}}\right] \\
v_{12}=v_{f} v_{f}+v_{m} v_{m} \\
v_{23}=v_{f} v_{f}+v_{m} v_{m} *\left[\frac{1+v_{m}-v_{12} E_{m} / E_{11}}{1-v_{m}^{2}+v_{m} v_{12} E_{m} / E_{11}}\right] \\
G_{12}=G_{m} *\left[\frac{G_{f}+G_{m}+\left(G_{f}-G_{m}\right) * v_{f}}{G_{f}+G_{m}-\left(G_{f}-G_{m}\right) * v_{f}}\right] \\
G_{23}=\frac{E_{22}}{2\left(1+v_{23}\right)}
\end{gathered}
$$

Elastic constants of Bi-woven fibers

$$
\begin{aligned}
& {\left[\frac{2}{E_{1}} \frac{E_{1}\left(E_{1}+\left(1-v_{12}^{2}\right) E_{2}\right)-v_{12}^{2} E_{2}^{2}}{E_{1}\left(E_{1}+2 E_{2}\right)+\left(1+2 v_{12}^{2}\right) E_{2}^{2}}\right]^{U D}=\left[\frac{1}{E_{1}}\right]^{W F}} \\
& {\left[\frac{4}{E_{1}} \frac{v_{12} E_{2}\left(E_{1}-v_{12}^{2} E_{2}\right)}{E_{1}\left(E_{1}+2 E_{2}\right)+\left(1+2 v_{12}^{2}\right) E_{2}^{2}}\right]^{U D}=\left[\frac{v_{12}}{E_{1}}\right]^{W F}} \\
& {\left[\frac{1}{E_{1}} \frac{E_{1}\left(v_{12}+v_{23}+v_{12} v_{23}\right)+v_{12}^{2} E_{2}}{E_{1}+\left(1+2 v_{12}\right) E_{2}}\right]^{U D}=\left[\frac{v_{13}}{E_{1}}\right]^{W F}}
\end{aligned}
$$

$$
\begin{gathered}
{\left[\frac{\left(1-v_{23}^{2}\right) E_{1}^{2}+\left(1+2 v_{12}+2 v_{12} v_{23}\right) E_{1} E_{2}-v_{12}^{2} E_{2}^{2}}{E_{1} E_{2}\left(E_{1}+\left(1+2 v_{12}\right)\right) E_{2}}\right]^{U D}} \\
=\left[\frac{1}{E_{3}}\right]^{W F} \\
{\left[\frac{1}{G_{12}}\right]^{U D}=\left[\frac{1}{G_{12}}\right]^{W F}} \\
{\left[\frac{1+v_{23}}{E_{2}}+\frac{1}{2 G_{12}}\right]^{U D}=\left[\frac{1}{G_{13}}\right]^{W F}}
\end{gathered}
$$

Elastic constants of FRP honeycomb core [Ref. 13]

$$
\begin{aligned}
E_{x} & =\left(\frac{4}{\sqrt{3}}\right)\left(\frac{t}{l}\right)^{3} E_{1} \\
E_{y} & =\left(\frac{4}{\sqrt{3}}\right)\left(\frac{t}{l}\right)^{3} E_{1} \\
E_{z} & =\left(\frac{t}{l}\right) E_{1} \\
G_{x y} & =\left(\frac{\sqrt{3} \gamma}{2}\right)\left(\frac{t}{l}\right)^{3} E_{1} \\
G_{x z} & =\left(\frac{\gamma}{\sqrt{3}}\right)\left(\frac{t}{l}\right) G_{12} \\
G_{y z} & =\left(\frac{\sqrt{3} \gamma}{2}\right)\left(\frac{t}{l}\right) G_{12} \\
v_{x y} & =1 \\
v_{x z} & =0.001 \\
v_{y z} & =0.001
\end{aligned}
$$




\section{Nomenclature}

\begin{tabular}{|c|c|}
\hline Symbol & Description \\
\hline$\rho_{f}$ & Density of fiber \\
\hline$\rho_{m}$ & Density of matrix \\
\hline$\rho_{c}$ & Density of composite \\
\hline$v_{f}$ & Volume fraction of matrix \\
\hline$v_{m}$ & Volume fraction of matrix \\
\hline$E_{f}$ & Elastic modulus of fiber \\
\hline$E_{m}$ & Elastic modulus of matrix \\
\hline$G_{f}$ & Shear modulus of fiber \\
\hline$G_{m}$ & Shear modulus of matrix \\
\hline$v_{f}$ & Poisson's ratio of fiber \\
\hline$v_{m}$ & Poisson's ratio of matrix \\
\hline$E_{1}$ & Elastic modulus of FRP lamina in $\mathrm{x}$ direction \\
\hline$E_{2}$ & Elastic modulus of FRP lamina in y direction \\
\hline$v_{12}$ & Poisson's ratio of FRP lamina in plane 1-2 \\
\hline$v_{13}$ & Poisson's ratio of FRP lamina in plane 1-3 \\
\hline$v_{23}$ & Poisson's ratio of FRP lamina in plane 2-3 \\
\hline$G_{12}$ & Shear modulus of FRP lamina in plane 1-2 \\
\hline$G_{13}$ & Shear modulus of FRP lamina in plane 1-3 \\
\hline$G_{23}$ & Shear modulus of FRP lamina in plane 2-3 \\
\hline$U D$ & Uni-directional composite \\
\hline$W F$ & Woven fiber composite \\
\hline$t, c$ & Thickness of cell wall, size of cell \\
\hline l & Side of hexagon \\
\hline$\theta$ & Half angle between inclined sides \\
\hline$\gamma$ & Technology coefficient ( 0.4 to 0.6$)$ \\
\hline$E_{x}$ & Young's modulus of FRP honeycomb core in $x$ direction \\
\hline$E_{y}$ & Young's modulus of FRP honeycomb core in $y$ direction \\
\hline$E_{z}$ & Young's modulus of FRP honeycomb core in $z$ direction \\
\hline$G_{x y}$ & Shear modulus of FRP honeycomb core in $x-y$ plane \\
\hline$G_{x z}$ & Shear modulus of FRP honeycomb core in $x$-z plane \\
\hline$G_{y z}$ & Shear modulus of FRP honeycomb core in $y$-z plane \\
\hline$v_{x y}$ & Poison's ratio of FRP honeycomb core in $x-y$ plane \\
\hline$v_{x z}$ & Poison's ratio of FRP honeycomb core in $x$-z plane \\
\hline$v_{y z}$ & Poison's ratio of FRP honeycomb core in $y$-z plane \\
\hline
\end{tabular}

